\title{
Mathias Perkams, Alexander M. Schilling (eds.). Griechische Philosophie und Wissenschaft bei den Ostsyrern: Zum Gedenken an Mār Addai Scher (1867- 1915)
}

Florence Jullien

\section{OpenEdition}

\section{Journals}

Édition électronique

URL : https://journals.openedition.org/abstractairanica/53114

DOI : 10.4000/abstractairanica.53114

ISSN : 1961-960X

Éditeur :

CNRS (UMR 7528 Mondes iraniens et indiens), Éditions de l'IFRI

Référence électronique

Florence Jullien, « Mathias Perkams, Alexander M. Schilling (eds.). Griechische Philosophie und Wissenschaft bei den Ostsyrern: Zum Gedenken an Mār Addai Scher (1867-1915) », Abstracta Iranica [En ligne], Volume 42-43 | 2021, document 3, mis en ligne le 30 décembre 2021, consulté le 13 décembre 2022. URL : http://journals.openedition.org/abstractairanica/53114 ; DOI : https://doi.org/10.4000/ abstractairanica. 53114

Ce document a été généré automatiquement le 13 décembre 2022.

Tous droits réservés 


\section{Mathias Perkams, Alexander M. Schilling (eds.). Griechische Philosophie und Wissenschaft bei den Ostsyrern: Zum Gedenken an Mār Addai Scher (1867-1915)}

Florence Jullien

\section{RÉFÉRENCE}

Mathias Perkams, Alexander M. Schilling (eds.). Griechische Philosophie und Wissenschaft bei den Ostsyrern: Zum Gedenken an Mār Addai Scher (1867-1915), (Transmissions 3), Berlin : Walter de Gruyter, 2020, i-ix p.-214 p., 12 tables. ISBN : 9783110668292.

Ce volume collectif est dédié à la mémoire d'Addaï Scher et publie les actes (augmentés de trois nouvelles contributions) d'un colloque tenu à Iéna en 2015 organisé à l'occasion du centenaire de sa mort violente en juin 2015. Il s'intéresse à l'héritage du savoir grec dans le système scolastique syriaque, et à sa mise en œuvre dans les productions littéraires. Les huit contributions éclairent en autant de facettes l'intégration de ce patrimoine écrit et conceptuel, en particulier dans le domaine des sciences (astronomie, grammaire, médecine, etc.) et de l'historiographie, chez les syriaques orientaux dont les œuvres sont devenues des lieux d'échanges entre les cultures grecque, syriaque, perse et islamique. M. Perkams, l'un des éditeurs, le rappelle à juste titre dans son introduction («Einleitung: Eine christliche Wissenstradition zwischen Griechen, Persern und Muslimen. Zur Bedeutung, Überlieferung und Erforschung des ostsyrischen Schrifttums ein Jahrhundert nach Addai Scher ", p. 1-12). La place majeure tenue par la paideia grecque dans le cursus formatif des écoles de théologie, avec son centre à Nisibe, et dans l'enseignement monastique eut un fort impact sur l'élaboration 
d'une culture mixte dont ces établissements se firent les relais sur un très vaste espace à travers les communautés de Perse, d'Inde et de Chine, et ce pendant plusieurs siècles.

2 A. Becker ("Mār Addai Scher and the Recovery of East Syrian Scholastic Culture", p. 13-28) retrace brièvement l'itinéraire d'A. Scher (1867-1915), issu d'une famille de prêtres chaldéens et éduqué dès l'âge de 12 ans au séminaire dominicain de Mossoul qui venait d'ouvrir ses portes. Devenu prêtre, il fut secrétaire de plusieurs évêques de Kirkouk avant d'être nommé, à l'âge de 35 ans, archevêque de Séert (Siirt) où il resta en fonction jusqu'à son assassinat. L'A. présente ses grands travaux consacrés au repérage et au catalogage des manuscrits syriaques de l'Orient, réalisés avec un esprit critique remarquable pour son époque, mis en pratique par exemple dans l'ordonnancement des hagiographies en fonction de la chronologie et non du calendrier liturgique. L'A. fournit également quelques réflexions sur le genre littéraire des causae, qu'il définit comme représentatif de la culture scolastique syriaque.

3 Ce sujet est également abordé par M. Perkams dans un deuxième article ("Ostsyrische Philosophie. Die Rezeption und Ausarbeitung griechischen Denkens in der Schule von Nisibis bis Barḥadbšabbā", p. 49-76) qui présente les principales sources sur ce genre littéraire.

U. Possekel (" "Go and Set Up for Yourselves Beautiful Laws...": The School of Nisibis and Institutional Autonomy in Late Antique Education", p. 29-48) dresse un bilan de l'état des recherches sur l'école de Nisibe, qui ont connu un fort accroissement ces dernières années. Elle souligne avec pertinence son indépendance institutionnelle par rapport à d'autres centres d'enseignement supérieur (comparaison avec les écoles philosophiques de l'empire romain et les écoles rabbiniques de l'époque sassanide). Elle rapproche les réglementations internes de cette école sur le rôle du directeur et de sa succession avec l'académie néoplatonicienne d'Athènes et l'école patriarcale juive de Palestine.

5 E. Fiori ("Dionysius the Areopagite and the East Syrian Mystics: The Phantom of a Greek", p. 77-98) aborde la littérature ascético-mystique des Syro-orientaux entre les VIe et VIIIe siècles, et plus particulièrement les points communs qu'il relève entre les écrits de Denis l'Aréopagite et Isaac le Syrien, puis Denis et Joseph Ḥazzāyā; il s'interroge sur leurs relations réciproques et leurs éventuels liens de dépendance, et conclut à une circulation de florilèges comportant des extraits des œuvres de l'Aréopagite qui ont pu influencer l'un et l'autre.

6 L'étude de M. Heimgartner revient sur les profondes connaissances philosophiques du patriarche Timothée Ier chargé par le calife al-Mahdi de traduire les Topiques d'Aristote ("Griechisches Wissen und Philosophie beim ostsyrischen Patriarchen Timotheos (780-823)", p. 99-118).

7 N. Kavvadas s'interroge sur les choix scolastiques des élites syro-orientales qui privilégièrent l'éducation rhétorique et philosophique grecque pour la formation et la controverse ; il met en évidence les mises en garde de certaines personnalités issues des milieux monastiques et mystiques à l'encontre de tels choix, tels Isaac de Ninive ou Dadǐšo` Qațraya. L’A. donne une analyse de vocabulaire ("Verdächtiges Prestige: Die griechische Bildung, der Jargon der Logik und die Konflikte der ostsyrischen Eliten”, p. 119-134).

8 Dans une étude philologique et comparative, A. M. Schilling enquête sur le Coran que le patriarche Timothée Ier et Denis bar Șalibi consultèrent, et à partir duquel ils 
commentèrent certaines sourates ("Der Koran des Katholikos-Patriarchen. Eine synoptische Analyse der sowohl in Timotheos' I. Dialog mit al-Mahdī als auch in Dionysios bar Șalībī's „Disput gegen die Nation der Araber“ zitierten Koranverse”, p. 135-156).

9 J. O. Schmitt ("Some Remarks on East Syrian Influences Found in Barhebraeus's Works", p. 157-176) examine les influences syro-orientales dans l'œuvre du maphrien syroorthodoxe Bar 'Ebrōyō et effectue un relevé de ses sources d'inspiration littéraires et philologiques. Il note que l'écrivain reprit directement certains auteurs orientaux dont il reconnaît l'autorité, spécialement dans ses ouvrages historiques et théologiques (avec les mystiques Isaac de Ninive, Jean de Dalyatha ou Joseph Ḥazzaya), mais aussi dans ses livres canoniques (travaux des patriarches Timothée Ier ou Ǐšo’ Bar Nun). Cette utilisation est aussi discernée dans ses études sur la grammaire (avec Élie de Nisibe).

On notera dans la bibliographie (p. 177-208) un manque d'homogénéité dans la liste des sources présentées en anglais et en allemand. Un index utile (p. 209-214) termine cet ouvrage. Les contributions ici réunies permettent de poser des jalons dans nos connaissances sur la transmission du savoir grec en monde syriaque oriental durant l'Antiquité tardive et surtout au début de l'époque médiévale, et sur le rôle joué par l'institution scolastique syriaque.

\section{AUTEURS}

FLORENCE JULLIEN

CNRS, CeRMI, Paris 